\title{
Prevalence of pulmonary arterial hypertension in severe chronic obstructive pulmonary disease patients attending tertiary care centre Ernakulam
}

\author{
Jilse George*, Niranjan A. V., Tara B. Nair, Minhaj
}

Department of Medicine, Govt. Medical College, Ernakulam, Kerala, India

Received: 07 January 2022

Accepted: 31 January 2022

\author{
*Correspondence: \\ Dr. Jilse George, \\ Email: drjilsegeorge@gmail.com
}

Copyright: $@$ the author(s), publisher and licensee Medip Academy. This is an open-access article distributed under the terms of the Creative Commons Attribution Non-Commercial License, which permits unrestricted non-commercial use, distribution, and reproduction in any medium, provided the original work is properly cited.

\begin{abstract}
Background: Chronic obstructive pulmonary disease (COPD) is an irreversible bronchial inflammation of lung airways and parenchyma. Various factors play an important role in occurrence and severity of pulmonary arterial hypertension $(\mathrm{PAH})$, a common in severe COPD. The objective of the study is to know the proportion of PAH in patients with severe COPD and to find the association between various factors.

Methods: 180 cases of severe COPD patients admitted in Government Medical College Ernakulum from January 2019December 2019, were enrolled into this cross-sectional descriptive study. Subject's history, clinical examination, anthropometric measurements, vitals, Arterial Blood Gas (ABG) analysis were done.

Results: Among 180 subjects, 148 (82.22\%) had mild PAH, $22(12.22 \%)$ subjects had moderate PAH and $10(5.56 \%)$ had severe PAH. Use of accessory muscle was the most elicited sign in the study with $174(96.67 \%) .170(94.44 \%)$ had cough and $169(93.89 \%)$ had breathlessness which were the most reported symptoms. Demographic variables and clinical features had no significant mean pulmonary artery pressure (mPAP) association. Grade 3 PAH groups were elder than others, which was statistically significant ( $\mathrm{p}<0.047)$. FEV1, Oxygen Saturation and ejection fraction were lowest in grade 3 PAH subjects. Respiratory rate, hemoglobin, PCV, tricuspid velocity, PaCO2 were highest in grade 3 PAH subjects being statistically significant $(\mathrm{p}<0.0001)$.

Conclusions: In our study, majority of severe COPD patients had mild PAH. There was an independent correlation between respiratory rate, hemoglobin, $\mathrm{PCV}$, tricuspid regurgitant velocity and $\mathrm{PaCO} 2$ with severity of $\mathrm{PAH}$.
\end{abstract}

Keywords: COPD, mPAP, PAH, Tricuspid valve regurgitant velocity

\section{INTRODUCTION}

Chronic obstructive pulmonary disease (COPD) is primarily characterised by the presence of airflow limitation resulting from airways inflammation and remodelling often associated with parenchymal destruction and the development of emphysema. ${ }^{1}$ Approximately $50 \%$ of patients with very severe COPD who undergo lung volume reduction surgery (LVRS) or lung transplantation have moderate to severe $\mathrm{PAH} 1$, a common complication of COPD. ${ }^{2}$ PAH defined by rightheart catheterization (RHC) showing precapillary pulmonary hypertension with a mean pulmonary artery pressure (mPAP) of $>25 \mathrm{mmHg}$ and a normal pulmonary artery wedge pressure (PCWP) of $<15 \mathrm{mmHg}{ }^{3} \mathrm{PAH}$ is usually mild to moderate and, nowadays, most of these patients in industrialised countries are undergoing longterm oxygen therapy which stabilises, attenuates, or sometimes reverses the progression of pulmonary hypertension. ${ }^{2}$

Potential causes proposed to explain the development of $\mathrm{PAH}$ in COPD include gas exchange abnormalities, destruction of the pulmonary vascular bed, alterations in 
respiratory mechanics, changes in intrinsic pulmonary vessel tone, and increased blood viscosity. ${ }^{4}$ Thrombosis and platelet dysfunction can be important in the development of PAH. Elevated plasma concentrations of D-dimers and fibrinopeptides A and B, in certain patients with PAH, are the proof of an abnormal intravascular coagulation process. Persistent dyspnea on exertion is the most frequent symptom; and it is present in almost patients even in the presence of mild hemodynamic abnormalities. Pulmonary function tests (PFT) will help to assess underlying lung abnormalities. Results of arterial blood gases usually show mild hypoxemia and hypocapnia. Transthoracic echocardiography (TTE) is a non-invasive screening test for patients with suspected Pulmonary Hypertension (PH). TTE estimates pulmonary artery systolic pressure (sPAP) and may provide additional information about the cause and consequences of PH. ${ }^{5}$ An ejection fraction $(\mathrm{EF})<50 \%$ is considered left ventricular dysfunction. Patients with COPD are at risk for left ventricular dysfunction; however, the results from the studies shows a disagreement regarding the association of LV dysfunction in COPD patients. ${ }^{6,7}$ Furthermore, Forced Expiratory Volume in the first second (FEV1) evaluation is crucial in estimating the severity of airflow limitation and until recently guided the clinical management of the disease. In addition, there is a direct correlation between FEV1 levels with the prognosis of these patients. ${ }^{8}$ In patients with COPD, malnutrition is often present and correlate with the severity of airway obstruction. ${ }^{9}$ Malnutrition can be diagnosed based on the presence of a Body Mass Index (BMI) of less than $18.5 \mathrm{~kg} / \mathrm{m} 2$ or based on weight loss (more than $10 \%$ irrespective of time or more than $5 \%$ over the last 3 months) combined with a reduced BMI (less than $20 \mathrm{~kg} / \mathrm{m} 2$ or less than $22 \mathrm{~kg} / \mathrm{m} 2$ if 70 years old or older). ${ }^{10}$

The objective of this study is to find the proportion of PAH in severe COPD patients and to find out the association between $\mathrm{PAH}$ and variables like haematological parameters, anthropometric measurements, vital signs, Forced Expiratory Volume (FEV1), EF and ABG.

\section{METHODS}

Patients admitted in Government Medical College Ernakulum from January 2019-December 2019, were enrolled into this cross-sectional descriptive study.

A total 180 COPD patients after applying the formula $4 \mathrm{pq} / \mathrm{d} 2$. As per study of Samareh et al, the prevalence of severe $\mathrm{PH}$ ( $\mathrm{p}$ value) is $13.7 \% .11 \mathrm{Q}$ value $=86.3$; $\mathrm{d}$ value (precision) $=5$. All consecutive Severe COPD patients admitted in medical wards and ICU of Govt. Medical College, Ernakulum till the sample size is attained.

\section{Inclusion and exclusion criteria}

Inclusion criteria for the study were all COPD exacerbation patients (as per GOLD criteria) whose airway obstruction, based on spirometric results, had an
FEV1/FVC ratio less than 0.7; also, they were given two puffs of salbutamol inhaler and, after $15 \mathrm{~min}$, if there was a not a $12 \%$ or $200 \mathrm{~cm} 3$ increase in FEV1, and the possibility of all other obstructive pulmonary diseases, such as bronchectasis, were ruled out. And FEV1<50\%.

\section{Data collection}

Study began after obtaining permission from research committee and institutional review board. As per the inclusion criteria COPD patients are selected. Thorough history and clinical examination done. After obtaining informed consent various tests are done. Initially anthropometric measurements are taken with weighing machine, measuring tape. Vitals are monitored with pulse oximeter, sphygmomanometer. ABG also done by taking blood in heparinised syringe and analysed using $A B G$ analyser. EF and tricuspid regurgitant flow velocity is calculated using echocardiogram. Tricuspid more than $3.4 \mathrm{~m} / \mathrm{s}$ is considered significant. Doppler Echo can approximate pulmonary artery systolic pressure (PASP) using

tricuspid valve velocity $(4 \mathrm{v} 2=\mathrm{TV}$ pressure gradient $)$, estimated CVP (=RA pressure), Bernoulli equation, PASP $=$ RVSP (in the absence of RVOTO or pulmonic stenosis)

$\mathrm{RVSP}=4 \mathrm{v} 2+\mathrm{CVP}$

Mean PAP can be approximated because mPAP = $0.61 \cdot$ sPAP +2 . Based on the echo PAH is classified into mild $(20-40 \mathrm{mmHg})$, moderate $(41-55 \mathrm{mmHg})$ and severe PAH (>55 mmHg). Then each variable is compared univariably for its association with $\mathrm{PAH}$.

\section{Data management and statistical analysis}

Data was analysed using Statistical package for social sciences (SPSS) statistical software. Descriptive statistics was used to find out mean, standard deviation, minimum, maximum and range for the quantitative variables. The association between the demographic variables and grades of pulmonary artery pressure were analysed by chi square test. Chi square test was used to find out association between clinical features and grades of PAH. One way ANOVA was used to find out the difference between grades of pulmonary artery pressure for age and other quantitative variables such as BMI, systolic blood pressure (SBP), diastolic blood pressure (DBP), pulse, saturation, respiratory rate (RR), total count, FEV1, platelet, tricuspid regurgitant velocity, partial pressure of carbon dioxide (PaCO2) etc.

\section{RESULTS}

\section{Basic characteristics}

A total of 180 patients were recruited in the study, in which $167(92.78 \%)$ were male and $13(7.22 \%)$ were female. The mean age of the patients was 63.49. Table 1 shows the 
descriptive statistics for demographic and outcome variables related to the patients.

Among 180 subjects, 148 (82.22\%) had mild PAH, 22 $(12.22 \%)$ subjects had moderate PAH and $10(5.56 \%)$ had severe PAH. Use of accessory muscle was the most elicited sign in the study with $174(96.67 \%) .170(94.44 \%)$ had cough and $169(93.89 \%)$ had breathlessness which were the most reported symptoms (Table 2).

Symptoms like abdominal distension, pedal edema, abdominal pain, reduced urinary output, Hemoptysis, JVP and FEV1 were found to be statistically significant with association of grades of PAH (Table 3 ).

The association between different grades of PAH and variables are shown in Table $4 . \mathrm{SPO} 2, \mathrm{RR}, \mathrm{Hb}, \mathrm{PCV}$, FEVI, Tricuspid regurgitant velocity, $\mathrm{PaCo} 2$ showed statistically significant difference.

There was no statistically significant difference between different grades of pulmonary artery pressure and age group $(p>0.69)$, gender $(p>0.257)$ and socio-economic status $(\mathrm{p}>0.222)$.

Table 1: Descriptive statistics for demographic and outcome variables.

\begin{tabular}{|c|c|c|c|c|c|}
\hline Variance & Range & Minimum & Maximum & Mean & SD \\
\hline Age & 57 & 35 & 92 & 63.49 & 9.92 \\
\hline SBP & 102 & 86 & 188 & 133.77 & 16.81 \\
\hline DBP & 58 & 42 & 100 & 79.71 & 8.71 \\
\hline Pulse & 72 & 54 & 126 & 81.21 & 12.55 \\
\hline BMI & 11.30 & 17.60 & 28.90 & 22.79 & 2.53 \\
\hline $\mathrm{SPO}_{2}$ & 7 & 87 & 94 & 91.66 & 1.54 \\
\hline $\mathbf{R R}$ & 23 & 19 & 42 & 25.11 & 4.50 \\
\hline Hb & 5.40 & 13 & 18.40 & 15.52 & 1.29 \\
\hline PCV & 53.40 & 4.60 & 56 & 45.77 & 4.97 \\
\hline Platelet & 2 & 1.50 & 3.5 & 2.43 & 0.52 \\
\hline TC & 7322 & 6130 & 13452 & 9177.38 & 1626.93 \\
\hline FEV 1 & 23 & 26 & 49 & 39.33 & 6.87 \\
\hline Tricuspid regurgitant velocity & 2.80 & 1.60 & 4.40 & 2.50 & 0.62 \\
\hline EF & 66 & 4 & 70 & 56.55 & 8.06 \\
\hline $\mathrm{PaCO}_{2}$ & 39 & 36 & 75 & 47.86 & 6.94 \\
\hline PAP & 45.75 & 17.25 & 63 & 30.10 & 10.46 \\
\hline
\end{tabular}

Table 2: Frequency distribution of variables.

\begin{tabular}{|c|c|c|c|}
\hline Variables & & Frequency & Percentage \\
\hline \multirow{7}{*}{ Age group } & $<40$ & 2 & 1.11 \\
\hline & $41-50$ & 10 & 5.56 \\
\hline & $51-60$ & 53 & 29.44 \\
\hline & $61-70$ & 73 & 40.56 \\
\hline & $71-80$ & 33 & 18.33 \\
\hline & $81-90$ & 7 & 3.89 \\
\hline & $>90$ & 2 & 1.11 \\
\hline \multirow{2}{*}{ Gender } & Male & 167 & 92.78 \\
\hline & Female & 13 & 7.22 \\
\hline \multirow{5}{*}{ Socioeconomic } & Upper & 10 & 5.56 \\
\hline & Upper middle & 28 & 15.56 \\
\hline & Lower middle & 72 & 40.00 \\
\hline & Upper lower & 55 & 30.56 \\
\hline & Lower & 15 & 8.33 \\
\hline \multirow{2}{*}{ Breathlessness } & Absent & 11 & 6.11 \\
\hline & Present & 169 & 93.89 \\
\hline \multirow{2}{*}{ Abdominal Distension } & Absent & 146 & 81.11 \\
\hline & Present & 34 & 18.89 \\
\hline \multirow{2}{*}{ Pedal edema } & Absent & 151 & 83.89 \\
\hline & Present & 29 & 16.11 \\
\hline \multirow{2}{*}{ Abdominal Pain } & Absent & 166 & 92.22 \\
\hline & Present & 14 & 7.78 \\
\hline
\end{tabular}




\begin{tabular}{|c|c|c|c|}
\hline Variables & & Frequency & Percentage \\
\hline \multirow{2}{*}{ Reduced urinary output } & Absent & 167 & 92.78 \\
\hline & Present & 13 & 7.22 \\
\hline \multirow{2}{*}{ Chest pain } & Absent & 169 & 93.89 \\
\hline & Present & 11 & 6.11 \\
\hline \multirow{2}{*}{ Hemoptysis } & Absent & 173 & 96.11 \\
\hline & Present & 7 & 3.89 \\
\hline \multirow{2}{*}{ Cough } & Absent & 10 & 5.56 \\
\hline & Present & 170 & 94.44 \\
\hline \multirow{2}{*}{ Fever } & Absent & 162 & 90.00 \\
\hline & Present & 18 & 10.00 \\
\hline \multirow{2}{*}{ Jaundice } & Absent & 170 & $10(94.44$ \\
\hline & Present & 10 & 5.56 \\
\hline \multirow{2}{*}{ Clubbing } & Absent & 165 & 91.67 \\
\hline & Present & 15 & 8.33 \\
\hline \multirow{2}{*}{ Accessory muscles } & Absent & 6 & 3.33 \\
\hline & Present & 174 & 96.67 \\
\hline \multirow{2}{*}{ Jugular venous pressure (JVP) } & Absent & 156 & 86.67 \\
\hline & Present & 24 & 13.33 \\
\hline \multirow{3}{*}{ Pulmonary artery pressure (PAP) } & Mild & 148 & 82.22 \\
\hline & Moderate & 22 & 12.22 \\
\hline & Severe & 10 & 5.56 \\
\hline
\end{tabular}

Table 3: Association of grades of PAH and symptoms.

\begin{tabular}{|c|c|c|c|c|c|c|c|}
\hline Variables & & Mild & Moderate & Severe & Total & $\begin{array}{l}\text { Chi- } \\
\text { square }\end{array}$ & $P$ value \\
\hline \multirow{2}{*}{ Breathlessness } & Absent & 10 & 1 & 0 & 11 & \multirow{2}{*}{0.85} & \multirow{2}{*}{$>0.654$} \\
\hline & Present & 138 & 21 & 10 & 169 & & \\
\hline \multirow{2}{*}{$\begin{array}{l}\text { Abdominal } \\
\text { distension }\end{array}$} & Absent & 136 & 10 & 0 & 146 & \multirow{2}{*}{72.42} & \multirow{2}{*}{$<0.0001$} \\
\hline & Present & 12 & 12 & 10 & 34 & & \\
\hline \multirow{2}{*}{ Pedal edema } & Absent & 140 & 11 & 0 & 29 & \multirow{2}{*}{83.31} & \multirow{2}{*}{$<0.0001$} \\
\hline & Present & 8 & 11 & 10 & 151 & & \\
\hline \multirow{2}{*}{ Abdominal pain } & Absent & 146 & 16 & 4 & 166 & \multirow{2}{*}{58.2} & \multirow{2}{*}{$<0.0001$} \\
\hline & Present & 2 & 6 & 6 & 14 & & \\
\hline \multirow{2}{*}{$\begin{array}{l}\text { Reduced urinary } \\
\text { output }\end{array}$} & Absent & 146 & 16 & 5 & 13 & \multirow{2}{*}{48.12} & \multirow{2}{*}{$<0.0001$} \\
\hline & Present & 2 & 6 & 5 & 167 & & \\
\hline \multirow{2}{*}{ Chest pain } & Absent & 140 & 20 & 9 & 11 & \multirow{2}{*}{0.73} & \multirow{2}{*}{$>0.694$} \\
\hline & Present & 8 & 2 & 1 & 169 & & \\
\hline \multirow{2}{*}{ Hemoptysis } & Absent & 145 & 21 & 7 & 7 & \multirow{2}{*}{19.64} & \multirow{2}{*}{$<0.0001$} \\
\hline & Present & 3 & 1 & 3 & 173 & & \\
\hline \multirow{2}{*}{ Cough } & Absent & 8 & 2 & 0 & 10 & \multirow{2}{*}{1.12} & \multirow{2}{*}{$>0.571$} \\
\hline & Present & 140 & 20 & 10 & 170 & & \\
\hline \multirow{2}{*}{ Fever } & Absent & 134 & 18 & 10 & 8 & \multirow{2}{*}{2.8} & \multirow{2}{*}{$>0.247$} \\
\hline & Present & 14 & 4 & 0 & 162 & & \\
\hline \multirow{2}{*}{ Jaundice } & Absent & 144 & 19 & 7 & 10 & \multirow{2}{*}{16.42} & \multirow{2}{*}{$<0.0003$} \\
\hline & Present & 4 & 3 & 3 & 170 & & \\
\hline Clubhino & Absent & 137 & 19 & 9 & 15 & 1 & $>0607$ \\
\hline & Present & 11 & 3 & 1 & 165 & 1 & 20.001 \\
\hline & Absent & 6 & 0 & 0 & 6 & 134 & $>0512$ \\
\hline Accessory muscles & Present & 142 & 22 & 10 & 174 & 1.54 & 30.512 \\
\hline IVP & Absent & 138 & 7 & 7 & 152 & 56.7 & $<0.0001$ \\
\hline JVP & Present & 10 & 15 & 3 & 28 & 50.1 & $<0.0001$ \\
\hline $\mathrm{PaCO}_{2}$ & $<45$ & 66 & 3 & 1 & 70 & 1144 & 03 \\
\hline $\mathrm{raCO}_{2}$ & $>45$ & 82 & 19 & 9 & 110 & 11.44 & -0.000 \\
\hline & $32-50$ & 144 & 14 & 3 & 161 & 1829 & $<00001$ \\
\hline FEV 1 & $<30$ & 4 & 8 & 7 & 19 & 10.29 & 0.0001 \\
\hline
\end{tabular}


Table 4: Comparison of quantitative variables with different grades of pulmonary arterial pressure.

\begin{tabular}{|lllll|}
\hline Variable & Grade I & Grade II & Grade III & P value \\
\hline Age & $62.66 \pm 9.92$ & $66.77 \pm 9.88$ & $68.60 \pm 8.14$ & $<0.047$ \\
\hline SBP & $133.59 \pm 16.65$ & $132.18 \pm 17.96$ & $139.80 \pm 18.07$ & $>0.477$ \\
\hline DBP & $79.93 \pm 8.76$ & $77.64 \pm 10.02$ & $81.00 \pm 3.68$ & $>0.466$ \\
\hline Pulse & $80.53 \pm 11.92$ & $83.09 \pm 14.11$ & $87.10 \pm 17.65$ & $>0.211$ \\
\hline BMI & $23.00 \pm 2.40$ & $22.05 \pm 3.07$ & $21.36 \pm 2.71$ & $>0.475$ \\
\hline SPO2 & $92.02 \pm 1.19$ & $90.45 \pm 1.84$ & $88.90 \pm 1.52$ & $<0.0001$ \\
\hline RR & $23.57 \pm 2.78$ & $31.27 \pm 4.31$ & $34.40 \pm 2.76$ & $<0.0001$ \\
\hline Hb & $14.90 \pm 0.92$ & $16.97 \pm 0.91$ & $17.95 \pm 0.30$ & $<0.0001$ \\
\hline PCV & $44.44 \pm 4.28$ & $50.73 \pm 2.80$ & $54.46 \pm 1.69$ & $<0.0001$ \\
\hline Platelet & $2.41 \pm 0.52$ & $2.48 \pm 0.51$ & $2.54 \pm 0.55$ & $>0.666$ \\
\hline TC & $9101.79 \pm 1595.32$ & $9758.91 \pm 2065.96$ & $9016.80 \pm 678.84$ & $>0.202$ \\
\hline FEV1 & $40.90 \pm 6.02$ & $33.36 \pm 6.48$ & $29.20 \pm 3.43$ & $<0.0001$ \\
\hline $\begin{array}{l}\text { Tricuspid } \\
\text { regurgitant velocity }\end{array}$ & $3.11 \pm 0.30$ & $4.21 \pm 0.21$ & $4.84 \pm 0.08$ & $<0.0001$ \\
\hline EF & $57.61 \pm 7.94$ & $52.14 \pm 8.03$ & $50.60 \pm 4.06$ & $<0.0005$ \\
\hline PaCO2 & $46.26 \pm 5.70$ & $54.50 \pm 7.78$ & $56.90 \pm 7.14$ & $<0.0001$ \\
\hline
\end{tabular}

\section{DISCUSSION}

In this cross-sectional descriptive study, the prevalence and predictors associated with patients with COPD were examined. The male preponderance evident in this study was similar to the one conducted by Mahishale et al which was also focussed in India (Karnataka), had $73.9 \%$ of male patients and study by Fekri et al in Iran, also had male predominance of $75 \% .^{12,13}$

Among 180 patients, $148(82.22 \%)$ patients had mild PAH, $22(12.22 \%)$ had moderate PAH and $10(5.56 \%)$ had severe PAH. The study conducted by Fekri et al showed severe $\mathrm{PH}$ at $13.7 \% .^{11}$ The prevalence of severe $\mathrm{PH}$ in COPD patients range from 5 to $13.5 \%$ and, in most cases, the prevalence has been $10 \% .^{11}$ Indian study by Gupta et al also showed prevalence of severe PAH was $17.65 \%$ in COPD patients. ${ }^{14}$ So in our study the prevalence of severe $\mathrm{PAH}$ is lower than the studies conducted earlier.

FEV1, oxygen saturation and ejection fraction was lowest in grade 3 pulmonary arterial hypertension subjects. Respiratory rate, hemoglobin, PCV, tricuspid velocity, $\mathrm{PaCO} 2$ were highest in grade 3 pulmonary arterial hypertension subjects which was statistically significant. In the study conducted by Fekri et al also showed the progressive development of PAH in COPD patients and their relationship with increased $\mathrm{PCV}$, ejection fraction, and hypoxia. ${ }^{11}$ Fekri et al in his study also showed association of BMI with PAH but our study did not show any association. This may be because of our small sample size of 180 compared to 1477 and also our study period was of 1 year duration.

\section{CONCLUSION}

In our study, majority of severe COPD patients had mild PAH. There was an independent correlation between respiratory rate, hemoglobin, $\mathrm{PCV}$, tricuspid regurgitant velocity and $\mathrm{PaCO} 2$ with severity of $\mathrm{PAH}$.

Funding: No funding sources

Conflict of interest: None declared

Ethical approval: The study was approved by the Institutional Ethics Committee

\section{REFERENCES}

1. Barnes PJ, Celli BR. Systemic manifestations and comorbidities of COPD. European respiratory journal. 2009;33(5):1165-85.

2. Chaouat A, Naeije R, Weitzenblum E. Pulmonary hypertension in COPD. European Respiratory Journal. 2008;32(5):1371-85.

3. Farber HW, Loscalzo J. Pulmonary arterial hypertension. New England Journal of Medicine. 2004;351(16):1655-65.

4. Lee-Chiong Jr TL, Matthay RA. Pulmonary hypertension and cor pulmonale in COPD. InSeminars in respiratory and critical care medicine. 2003;4(3):263-72.

5. Montani D, Günther S, Dorfmüller P, Perros F, Girerd $\mathrm{B}$, Garcia $\mathrm{G}$ et al. Pulmonary arterial hypertension. Orphanet journal of rare diseases. 2013;8(1):1-28.

6. Murphy ML, Adamson J, Hutcheson F. Left ventricular hypertrophy in patients with chronic bronchitis and emphysema. Ann Intern Med. 1974;81:307-13. 
7. Fluck DC, Chandrasekar RG, Gardner FV. Left ventricular hypertrophy in chronic bronchitis. Br Heart J. 1966;28:92-7.

8. Kakavas S, Kotsiou OS, Perlikos F, Mermiri M, Mavrovounis G, Gourgoulianis K et al. Pulmonary function testing in COPD: looking beyond the curtain of FEV1. NPJ primary care respiratory medicine. 2021;31(1):1-1.

9. Mete B, Pehlivan E, Gülbaş G, Günen H. Prevalence of malnutrition in COPD and its relationship with the parameters related to disease severity. Int $\mathrm{J}$ Chron Obstruct Pulmon. Dis. 2018;13:3307-12.

10. Cederholm T. ESPEN guidelines on definitions and terminology of clinical nutrition. Clin Nutr. 2017;36:49-64.

11. Fekri MS, Torabi M, Shoul SA, Mirzaee M. Prevalence and predictors associated with severe pulmonary hypertension in COPD. The American journal of emergency medicine. 2018;36(2):277-80.

12. Mahishale V, Patil B, Rathi A, Sindhuri A, Eti A. Screening of Chronic Obstructive Pulmonary Disease patients for pulmonary arterial hypertension using two-dimensional transthoracic doppler echocardiography in tertiary care hospital in India. Heart India. 2015;3(3):66.

13. Fekri MS, Bajgani SM, Rasti A, Yazdani R, Mollaie HR. Detection of helicobacter pylori in bronchoalveolar lavage of patients with chronic obstructive pulmonary disease by real time polymerase chain reaction. Jundishapur journal of microbiology. 2015;8(1).

14. Gupta NK, Agrawal RK, Srivastav AB, Ved ML. Echocardiographic evaluation of heart in chronic obstructive pulmonary disease patient and its corelation with the severity of disease. Lung India: official organ of Indian Chest Society. 2011;28(2):105.

Cite this article as: George J, Niranjan AV, Nair TB, Minhaj. Prevalence of pulmonary arterial hypertension in severe chronic obstructive pulmonary disease patients attending tertiary care centre Ernakulam. Int J Basic Clin Pharmacol 2022;11:161-6. 